\title{
Ler, traduzir, ensinar
}

\author{
To read, to translate, and to teach
}

\section{Salma Tannus Muchail ${ }^{*}$}

Pontifícia Universidade Católica de São Paulo (PUC-SP), São Paulo, Brasil

\section{Resumo}

A experiência de traduzir textos filosóficos (no caso, especificamente textos de Michel Foucault) permite o levantamento de reflexões sobre analogias possíveis entre o trabalho de tradução, por um lado e, por outro, a leitura e o ensino filosóficos. Também conduzà hipótese de um parentesco possível entre a tradução e a redação de apresentações e prefácios.

Palavras-chave: Tradução. Leitura e ensino filosóficos. Apresentações e prefácios.

\section{Abstract}

The experience of translating philosophical texts (in this case, specifically speaking, texts of Michel Foucault) brings about some reflections on possible analogies between, on the one hand, the translating work itself, and, on the other hand, the philosophical reading and teaching. It also leads to a hypothesis of a possible affinity between the translation and the redaction of presentations and prefaces.

Keywords: Translation. Philosophical reading and teaching. Presentations and prefaces.

* STM: Pós doutora, e-mail: salma@pucsp.br 


\section{Introdução}

O primeiro livro de Foucault que traduzi foi Les Mots et les choses (FOUCAULT, 1966) ${ }^{1}$. O trabalho inicialmente solicitado consistiria em adaptar a tradução portuguesa já existente às construções linguísticas brasileiras. A solicitação foi substituída, a meu pedido, pela elaboração de outra tradução, trabalho que eu julgava mais exequível e procedente. A meu olhar retrospectivo, creio hoje que só aceitei aquela tarefa em razão de um engano, ou melhor, de minha ignorância: eu não sabia, nem de longe, o desafio que me espreitava. Era um texto vigoroso, em estilo filosoficamente denso e literariamente quase barroco. Empenhei-me com o maior entusiasmo durante mais de dois anos. A tarefa era exuberante e, além de minha quase total inexperiência, ela exigiu consultas não somente a dicionários especializados e não especializados, como ainda a pessoas que conheciam bem as duas línguas e, principalmente, tinham familiaridade com o repertório filosófico. Lembro-me, por exemplo, de ter procurado junto a uma confiável conhecedora da língua francesa (Profa. Jeanne Marie Gagnebin), recém-chegada ao Brasil, as melhores adequações para traduzir expressões metafóricas abundantemente usadas por Foucault. Também convoquei uma amiga (Gláucia Balieiro) que conhecia muito bem a língua portuguesa, para me auxiliar nas dúvidas de construção linguística brasileira. A tradução foi feita em uma antiga máquina de datilografar alemã, tamanho portátil, que eu havia encomendado para a inclusão de tipos brasileiros. Os outros instrumentos? Borracha e pincel para limpar os vestígios da borracha... Concluída a tradução, a máquina datilográfica havia chegado ao limite de uso e foi jogada ao lixo. Uma (pequena) parte do (pequeno) pagamento que recebi foi destinado à "consultora" brasileira e o restante, usei - sem nenhuma hesitação nem pudor - na compra de peças de praia incluídas na bagagem de um merecido descanso em Salvador. Tomei a iniciativa de fazer chegar um exemplar da tradução ao Prof. Michel Foucault, por meio de um colega e amigo (Prof. Arley Ramos Moreno) que viajara para Paris

A primeira edição da tradução brasileira saiu em 1981, pela Editora Martins Fontes, sob o título As Palavras e as coisas. Uma arqueologia das ciências humanas. 
logo após a publicação. O exemplar foi acompanhado de uma pequena carta de encaminhamento. A resposta de Foucault surpreendeu-me: ela foi enviada pessoalmente por correio postal e, nela, seu autor mostrava-se gentilmente grato pelo meu trabalho. Hoje, tomo a iniciativa de agregar ao presente texto a inédita divulgação desta reposta a ser acolhida, creio, como um registro histórico:

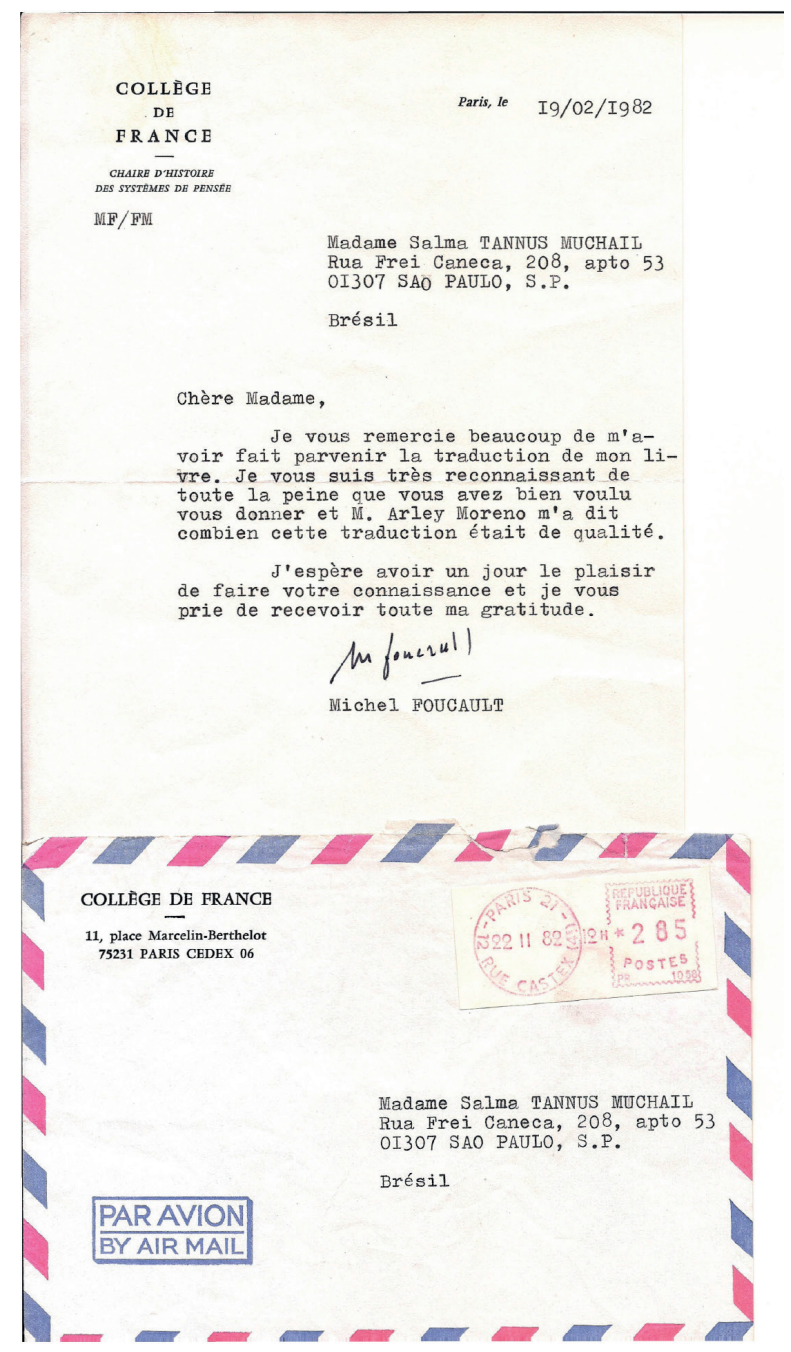


Depois da tradução de outros autores, tive oportunidade de voltar aos escritos de Foucault para me dedicar ao exercício imprevisivelmente rico de traduzi-los a quatro mãos. O Prof. Márcio Alves da Fonseca e eu traduzimos juntos L'Herméneutique du sujet (FOUCAULT, 2001) $)^{2}$ e Introduction à l'Anthropologie de Kant - Genèse et structure de l'Anthropologie de Kant (FOUCAULT, 2008) ${ }^{3}$. Como se sabe, A Hermenêutica do sujeito é a versão escrita do Curso ministrado em 1982, no Collège de France e que, por isto mesmo, mantém certo estilo entre o coloquial e o didático, sem perda da enorme erudição que substancia tanto os ditos quanto os escritos de Foucault. Gênese e estrutura da Antropologia de Kant, mais conhecida como Tese complementar, tardiamente publicada, foi elaborada no início da trajetória intelectual de Foucault, como parte do seu doutorado e que, por isto mesmo, sem nenhuma perda na originalidade da reflexão, guarda traços de um trabalho mais estritamente acadêmico. Recentemente fui convidada a traduzir escritos que pareciam bem opostos aos anteriores, particularmente ao da primeira tradução. São textos curtos - Le Corps utopique e Les Hétérotopies (FOUCAULT, 2009) ${ }^{4}$ reunidos em um pequeno volume (menos de 60 páginas contra as mais de 400 de As Palavras e as coisas), estilo nada acadêmico, escrita desprovida de remissões e citações. E eis que, tanto tempo e tantas experiências depois, vim a cair em uma cilada semelhante à da primeira tradução: tratava-se de mais um desafio e, assim como o primeiro, tão árduo quanto prazeroso. Traduzir, afinal, é como um jogo: surpreende e instiga, diverte e ensina. reflexões.

É a partir deste aprendizado que recolho e partilho algumas

1. Primeiro, parece-me que traduzir textos de filosofia é uma atividade com características aparentadas às da leitura filosófica, isto é, as que praticamos no ensino da filosofia. Com efeito, estas atividades

\footnotetext{
Sob o título A Hermenêutica do sujeito, a primeira edição da tradução brasileira saiu em 2004, pela Editora Martins Fontes.

Sob o título Gênese e estrutura da Antropologia de Kant, a tradução brasileira saiu em 2011, pelas Edições Loyola.

4 Sob o título 0 Corpo utópico, As Heterotopias - Posfácio de Daniel Defert -, a tradução saiu em 2013, pela Editora N-1, em edição bilíngue. 0 presente texto é uma versão modificada de uma apresentação da tradução brasileira por ocasião do seu lançamento.
} 
envolvem dificuldades ou dilemas semelhantes, que podemos situar, esquematicamente, entre dois extremos:

- num polo extremo, pode-se dizer que a tradução não se limita a uma espécie de cópia de uma língua para outra, tanto quanto a leitura filosófica não é repetição ou mera reconstituição do texto lido;

- no outro extremo, da tradução não se espera extrapolar ou distorcer o texto original, assim como do leitor de filosofia espera-se respeito fiel ao autor lido.

Dois extemos aparentemente óbvios, mas, entre eles, o ponto de equilíbrio não é fácil. Com efeito, nestas atividades - traduzir, ler e ensinar - está em jogo a reelaboração de um pensamento para ao qual concorre - além, é claro, do próprio autor lido, ensinado ou traduzido - a responsabilidade filosófica do leitor, do professor ou do tradutor.

Muitos de nós, leitores e professores de filosofia, nos dedicamos à tradução. Traduzir é para nós um trabalho frequentemente solitário, que requer labor paciente e discrição. Desejável seria que a tradução resultasse tão "desapercebida" que o texto fluísse na língua para a qual foi traduzido como se fora sua língua original. Ademais, sabemos que, de modo geral, este trabalho é realizado como que "à margem" ou "ao lado" das atividades de leitura e ensino. Sabemos também que, ao mesmo tempo em que dispomos não mais que de um tempo "paralelo" para executá-lo, quase sempre somos pressionados pelos prazos das editoras.

Ora, se entendermos melhor que a atividade de tradução - além de constituir um meio de troca cultural - tem proximidades com a leitura e o ensino da filosofia, torna-se interessante explorá-la mais, dedicar-lhe um cuidado mais eficaz e um olhar mais atento. Neste sentido, a tradução pode vir a ser um particular exercício de pensar e repensar filosoficamente e, portanto, mais um instrumento de ensino e de corresponsabilidade filosófica.

2. Um segundo ponto para reflexão reside na hipótese de um possível parentesco entre o trabalho de traduzir e a elaboração de apresentações e prefácios. Assim como um texto traduzido não deve sobrepor-se 
ao original, um prefácio ou uma apresentação não deve "antecipar" a leitura do texto principal. No próprio Foucault encontramos lições modelares a este respeito. Recordo um conhecido exemplo. Quando solicitado a redigir um prefácio para a nova (2 $2^{\underline{a}}$.) edição de Histoire de la folie à l'âge classique (FOUCAULT, 1972), o conteúdo do prefácio é sua reticência em fazê-lo. Um prefácio, alerta Foucault - principalmente se escrito pelo próprio autor - significaria a imposição prévia de uma leitura regida pela sua soberana "autoridade": "ato primeiro com o qual começa a estabelecer-se a monarquia do autor, declaração de tirania". E continua: "Gostaria que um livro, pelo menos da parte de quem o escreveu nada fosse além das frases de que é feito; que ele não se desdobrasse nesse primeiro simulacro de si mesmo que é um prefácio, e que pretende fornecer sua lei a todos que, no futuro, venham a formar-se a partir dele" (FOUCAULT, 1972, p. 8) . E, para concluir, Foucault dialoga consigo mesmo, levantando uma objeção e fornecendo a resposta: - "Mas você acaba de fazer um prefácio! - Pelo menos é curto" (FOUCAULT, 1972, p. 8-9) ${ }^{5}$.

Ora, curiosamente, a elaboração das traduções mais recentes foi ocasião de um reencontro com aquele livro que primeiramente traduzi, As Palavras e as coisas, e nele, precisamente, o prefácio. É lá que Foucault introduzira as noções de utopia e heterotopia. Nada estranho do ponto de vista cronológico se lembrarmos as datas de origens dos textos. Com efeito, As Palavras e as coisas foi publicado em 1966 enquanto "O Corpo utópico" e "As Heterotopias" consistiram em conferências radiofônicas pronunciadas no final daquele mesmo ano. Por outro lado, porém, se não é estranho, este reencontro de tema torna-se especialmente significativo ao considerarmos que a divulgação da segunda conferência, inicialmente de circulação muito restrita, só ocorrerá efetivamente quase vinte anos depois, em 1984, quando, pouco antes de sua morte, o próprio Foucault autorizou sua publicação. O texto posteriormente publicado sofreu reelaborações que o adaptaram à forma da escritura, resultando, assim, em uma segunda versão, bastante diversa, aliás,

5 Cf. tradução brasileira de José Teixeira Coelho Netto, sob o título História da loucura na idade clássica. S. Paulo, Perspectiva, 5a.ed., 1997, p. VIII. 
do manuscrito original em sua expressão radiofônica ou sonora. A segunda versão recebeu novo título: “Des espaces autres” (FOUCAULT, 1994, p. 752-762) ${ }^{6}$. Assim, as peripécias envolvendo os textos - o primeiro e os últimos que traduzi - fazem do reencontro de temas entre eles mais que uma curiosidade: abrem, se quisermos, um novo espaço, um "espaço outro", uma "heterotopia", onde temas antigos podem ser repensados.

Senão, vejamos. Consideremos o prefácio de As Palavras e as coisas. Ali se expõe a questão do Outro em oposição ao Mesmo. E o Outro, em duplo sentido: como limite externo entre culturas e como diferenças internas em uma mesma cultura. É para discorrer sobre o "lugar" e o "espaço" do Outro, que Foucault faz uso das noções de utopia e heterotopia (principalmente esta última). Exemplifica, por assim dizer, estas noções, recorrendo a três casos buscados na literatura.

- O primeiro é a famosa passagem de Borges, que enumera aquela suposta e incongruente classificação chinesa dos animais: "os animais se dividem em: a) pertencentes ao imperador, b) embalsamados, c) domesticados, d) leitões, e) sereias, f) fabulosos, g) cães em liberdade, h) incluídos na presente classificação, i) que se agitam como loucos, j) inumeráveis, k) desenhados com um pincel muito fino de pelo de camelo, l) et cetera, m) que acabem de quebrar a bilha, n) que de longe parecem moscas" (FOUCAULT, 1966, p. 7)7 . Nesta classificação, o único espaço inteligível na esfera de nossa cultura é o da sequência alfabética.

- O segundo exemplo usado por Foucault é a relação de "vermes e serpentes" que Rabelais coloca na boca "acolhedora e

6 Cf. tradução brasileira de Inês de Autran Dourado Barbosa, sob o título "Outros espaços", publicada em Foucault - Estética: Literatura e Pintura, Música e Cinema (org., Manoel Barros das Motta), Col. Ditos e\& Escritos", vol. III, Rio de Janeiro, Forense Universitária, p.411-422. Mencionamos aqui a publicação de dois estudos, em português, a partir desta última versão: Carlos J. MARTINS, "Utopias e heterotopias na obra de Michel Foucault: pensar diferentemente o tempo, o espaço e a história" (em Rago, M., Orlandi,L. Veiga-Neto); orgs., Imagens de Foucault e Deleuze- ressonâncias nietzschianas, Rio de Janeiro, DP\&A, 2002, p. 85-198 e E.PASSETTI, "Heterotopia, anarquismo e pirataria" (em Rago, M., Veiga-Neto, orgs, Figuras de Foucault, Belo-Horizonte, Autêntica, 2. ed., 2008, p. 109-118).

7 Na tradução brasileira, p. IX. A classificação dos animais citada por Foucault é extraída de Jorge L. Borges, El idioma analítico de John Wilkins (em Otras Inquisiciones, Buenos Aires, Emecê Editores, 1960, p. 139-144). 
voraz" de um personagem: "Já não estou em jejum [....]. Por todo o dia de hoje estarão a salvo da minha saliva: Áspides, Anfisbenas, Anerudutos, Abedessimões, Alartas, Amóbatas, Apinaos, Alatrabãs, Aractes, Astérios, Alcarates, Arges, Aranhas, Ascálabos, Atélabos, Ascalobotas, Aemorróides...". Além da única vogal que os inicia, os nomes destes vermes e serpentes, só "cabem" em um espaço comum na medida em que todos eles "fervilham, como as sílabas que os nomeiam..." (FOUCAULT, 1966, p. 8) $)^{8}$.

- O terceiro caso é buscado em uma passagem de Lautréamont que descreve uma situação insólita comparando-a ao "encontro fortuito", sobre uma mesa de trabalho, - isto é, sobre uma mesma superfície espacial - entre "o guarda-chuva e a máquina de costura” (FOUCAULT, 1966, p. 8) ${ }^{9}$, objetos cuja vizinhança parece "incabível", quer dizer, sem lugar.

Com estes exemplos, e no solo da questão do Outro, o prefácio de As Palavras e as coisas introduz então aquelas duas noções, explicitando, mais especialmente, o significado das heterotopias. Inicialmente, Foucault refere-se à dimensão do heteróclito, no sentido etimológico de coisas que "aí são 'deitadas', 'colocadas', 'dispostas' em lugares a tal ponto diferentes, que é impossível encontrar-lhes um espaço de acolhimento, definir por baixo de umas e outras um lugar-comum". (FOUCAULT, 1966, p. 9). E em seguida:

As utopias consolam: é que, se elas não têm lugar real, desabrocham, contudo, num espaço maravilhoso e liso; abrem cidades com vastas avenidas, jardins bem plantados, regiões fáceis, ainda que o acesso a elas seja quimérico. As heterotopias inquietam, sem dúvida, porque solapam secretamente a linguagem, porque impedem de nomear isto e aquilo, porque fracionam os nomes comuns ou os emaranham, porque arruínam de antemão a 'sintaxe', e não somente aquela que constrói as frases - aquela, menos manifesta, que autoriza 'manter juntas' (ao lado e em

8 Na tradução brasileira, p. X-XI. A referência é extraída de Rabelais, Gargântua e Pantagruel (em Pantagruel, v. II, Cap. LXIV).

9 Na tradução brasileira, p. XI. A referência é extraída de Lautréamont, Chants de Moldoror (em Chant VI). 
frente umas das outras) as palavras e as coisas (FOUCAULT, 1966, p. 9) ${ }^{10}$.

As conferências radiofônicas pronunciadas em 1966 retomam aquelas duas noções, mas de maneira inusitada e em estilo inteiramente diverso. Esquivo-me aqui de arriscar um comentário prévio que, semelhantemente a uma "apresentação" ou a um "prefácio", se atreveria a "antecipar" a leitura direta dos textos. Imitando um pouco a lista de Borges ou o relato de Rabelais, restrinjo-me a oferecer um levantamento de temas, um rol de nomes que, em proporções diversas, ocupam os espaços das duas conferências: o espelho; fadas e duendes, gênios e gigantes; a morte e a alma, tumbas e cadáveres; bibliotecas e museus; casas de tolerância e clubes de repouso; maquiagens, máscaras, tatuagens; teatros, cinemas, bares; asilos e prisões; jardins orientais e tapetes voadores; o enigmático e o cifrado; o mistério, o secreto e o sagrado; o barco.

Como nas listagens de Borges ou de Rabelais, estas noções tão deslocadas umas das outras, são talvez passíveis de "incorporar-se" em um corpo utópico e achar "lugar" em espaços outros.

3. Para concluir, ainda uma consideração. $\mathrm{O}$ volume recente que reúne a publicação francesa (2009) das duas conferências, agora segundo a sua primeira versão, inclui também um texto da autoria de Daniel Defert. Companheiro de vida e de ideias de Michel Foucault, Defert oferece informações sobre as circunstâncias de elaboração e publicação dos textos e, mais que isto, uma preciosa reflexão sobre eles, sobre seu conteúdo e sobre sua forma. Este texto aparece, precisamente, como um posfácio, não um prefácio. E por que não? Para não "antecipar-se" à leitura dos próprios textos? A favor desta hipótese, realço uma das informações fornecidas por Defert. Ele faz ver, por um lado, que o grande livro, escrito na mesma época, isto é, As Palavras e as coisas, do qual, diz Defert, "Foucault esperava a provocação de rupturas no pensamento" (In: FOUCAULT, 2009, p. 42-43) ${ }^{11}$ não teria suscitado, propriamente,

${ }^{10}$ Na tradução brasileira, p. XII-XIII.

${ }^{11}$ Cf. D. DEFERT, "'Heterotopia': tribulations d'un concept entre Venise, Berlin et Los Angeles". Posface à Foucault, Les Corps utopique, Les Hétérotopies. Na tradução brasileira, p. 38. 
uma concepção nova de espaço (nem de urbanismo). Por outro lado, porém, "tribulações" teriam sido provocadas (particularmente entre arquitetos) por aquelas duas pequenas conferências posteriormente reelaboradas e adequadas à forma da escritura.

Junto a estas colocações de Defert, reconstituo uma distinção significativa entre a versão originária (radiofônica) e a versão posterior:

- a primeira versão (esta, mais recentemente publicada e traduzida) pertence a "uma linguagem menor", "um daqueles jogos literários nos quais Foucault tinha um prazer guloso, júbilo...";

- a segunda versão (esta, publicada em 1984) é aquela em que o júbilo é "decepado pela ascese da escritura, contenção que se lê na didática da conferência escrita" (In: FOUCAULT, 2009, p. 43) ${ }^{12}$.

Ora, se antes já dispúnhamos da segunda versão, com a publicação da primeira podemos agora aplicar-lhe as palavras de Defert: "os jogos literários ficam [...] finalmente retranscritos com todo respeito à integralidade sonora da qual nasceram" (In: FOUCAULT,2009, p. 43) ${ }^{13}$. A estas reflexões, afinal, poder-se-ia objetar:

- "Mas você acabou de 'adiantar-se' à leitura dos textos: uma apresentação? um quase prefácio' ?"

Ao que, parafraseando Foucault, eu apenas responderia:

- "Pelo menos é curto".

\section{Referências}

DEFERT, D. "Hétérotopie": Tribulations d'um concept entre Venise, Berlin et Los Angeles. In: FOUCAULT, M. Le corps utopique, Les hétérotopies. Présentation de Daniel Defert. Paris: Nouvelles Éditions Lignes, 2009. p. 37-61.

12 Na tradução brasileira, p. 38.

13 Na tradução brasileira, p. 38. 
DEFERT, D. "Heterotopia": Tribulações de um conceito entre Veneza, Berlim e Los Ângeles. In: FOUCAULT, M. O Corpo utópico, As heterotopias. Posfácio de Daniel Defert. Trad. Salma Tannus Muchail. São Paulo: N-1, 2013. p. 33-55.

FOUCAULT, M. Les mots et les choses. Une arquéologie des sciences humaines. Paris: Gallimard, 1966.

FOUCAULT, M. As palavras e as coisas. Uma arqueologia das ciências humanas. Trad. Salma Tannus Muchail. 8. ed. São Paulo: Martins Fontes, 1999.

FOUCAULT, M. L'Herméneutique du sujet. Cours au Collège de France, 19811982. Paris: Gallimard, 2001.

FOUCAULT, M. A Hermenêutica do sujeito. Trad. Márcio Alves da Fonseca e Salma Tannus Muchail. São Paulo: Martins Fontes, 2004.

FOUCAULT, M. Introduction à l'Anthropologie de Kant (Genèse et structure de l'Anthropologie de Kant. Paris: Vrin, 2008.

FOUCAULT, M. Gênese et estrutura da Antropologia de Kant. Trad. Márcio Alves da Fonseca e Salma Tannus Muchail. São Paulo: Loyola, 2011.

FOUCAULT, M. Le corps utopique, Les Hétérotopies. Présentation de Daniel Defert. Paris: Nouvelles Éditions Lignes, 2009.

FOUCAUlT, M. O corpo utópico, As Heterotopias. Posfácio de Daniel Defert. Trad. Salma Tannus Muchail. São Paulo: N-1, 2013.

FOUCAULT, M. Histoire de la folie à l'âge classique. 2. éd. Paris, Gallimard, 1972. FOUCAULT, M. História da loucura na idade clássica. Trad. José Teixeira Netto. 5. ed. São Paulo: Perspectiva, 1997.

FOUCAULT, M. Des espaces autres. In: Dits et écrits, v. IV. Paris: Gallmard, 1994. p. $752-762$.

FOUCAULT, M. Outros espaços. In: Foucault- Estética: Literatura e Pintura, Música e Cinema. Org. de Manoel Barros da Motta. Trad. Inês Autran Dourado Barbosa. Rio de Janeiro: Forense Universitária, 2001. p. 411-422. 
MARTINS, C. J. Utopias e heterotopias na obra de Michel Foucault: pensar diferentemente o tempo, o espaço e a história. In: Imagens de Foucault e Deleuzeressonâncias nietzschianas. Org. de Margareth Rago, Luís Orlandi, Alfredo Veiga-Neto. Rio de Janeiro: DP\&A, 2002. p. 85-198.

PASSETTI, E. Heterotopia, anarquismo e pirataria. In: Figuras de Foucault. Org. de Margareth Rago e Alfredo Veiga-Neto. 2. ed. Belo-Horizonte: Autêntica, 2008. p. 109-118.

Recebido: 08/10/2016

Received: 10/08/2016

Aprovado: $30 / 10 / 2016$

Approved: 10/30/2016 